Original Article

\title{
Influence of parity, type of delivery, and physical activity level on pelvic floor muscles in postmenopausal women
}

\author{
Larissa Ramalho Dantas Varella ${ }^{1)^{*}}$, Vanessa Braga Torres ${ }^{1)}$, \\ Priscylla Helouyse Melo Angelo ${ }^{1)}$, Maria Clara Eugênia de Oliveira ${ }^{1)}$, \\ Alef Cavalcanti Matias de Barros ${ }^{1)}$, Elizabel de Souza Ramalho Viana ${ }^{1)}$, \\ Maria Thereza de Albuquerque Barbosa Cabral Micussil) \\ 1) Department of Physical Therapy, Federal University of Rio Grande do Norte, Natal: Rio Grande do \\ Norte, Brazil
}

\begin{abstract}
Purpose] The aim of the present study was to assess the influence of parity, type of delivery, and physical activity level on pelvic floor muscles in postmenopausal women. [Subjects and Methods] This was an observational analytic cross-sectional study with a sample of 100 postmenopausal women, aged between 45 and 65 years, divided into three groups according to menopausal stage: hysterectomized and early and late postmenopause. Patients were assessed for sociodemographic and gyneco-obstetric factors and subjected to a muscle strength test and perineometry. Descriptive statistics, ANOVA, Kruskal-Wallis and multiple regression were applied. [Results] The results showed homogeneity in sociodemographic and anthropometric characteristics. There was no difference in pelvic floor muscle function among the three groups. Type of delivery, parity and physical activity level showed no influence on muscle function. [Conclusion] The findings demonstrate that parity, type of delivery, and physical activity level had no influence on pelvic floor muscle pressure in postmenopausal women. One hypothesis to explain these results is the fact that the decline in muscle function in postmenopausal women is related to the female aging process.

Key words: Physical examination, Muscle strength, Aging
\end{abstract}

(This article was submitted Oct. 26, 2015, and was accepted Dec. 1, 2015)

\section{INTRODUCTION}

Postmenopause is a period characterized by hormonal and organic changes caused by ovarian failure. Women are considered to be in this phase when they experience 12 months of amenorrhea (menopause). This period is divided into an early phase characterized by high FSH levels and a decline in serum estradiol levels and a late phase characterized by stabilization of hormone levels at around 6 months after menopause ${ }^{1-3)}$.

Hypoestrogenism, characteristic of this phase of a woman's life, is related to pelvic floor muscle (PFM) weakening due to progressive musculoaponeurotic and conjunctive atrophy. Estrogen acts on the tonus of these muscles by increasing the number and sensitivity of alpha-adrenergic receptors, urethral vascularization, and periurethral connective tissue, stimulating fibroblasts to produce collagen. Thus, estrogen plays an important role in the continence mechanism, since it increases urethra mucosa tropism and its decline may cause changes in the muscle complex resulting in pelvic floor dysfunction, such as urinary incontinence (UI), pelvic organ prolapse (POP), and sexual problems ${ }^{4}$.

In addition to hormonal disorders inherent to this period, other factors during a woman's life, such as parity, type of delivery, use of anesthesia during delivery, newborn weight, menopause, gynecological surgeries, smoking, chronic diseases,

\footnotetext{
*Corresponding author. Larissa Ramalho Dantas Varella (E-mail: larissavarella@yahoo.com)

(C)2016 The Society of Physical Therapy Science. Published by IPEC Inc.

This is an open-access article distributed under the terms of the Creative Commons Attribution Non-Commercial No Derivatives (by-nc-nd) License $<$ http://creativecommons.org/licenses/by-nc-nd/4.0/>.
} 
intestinal constipation, physical activity, hereditariness, use of drugs, and consumption of irritating substances ${ }^{5)}$, have been associated with changes in the PFM in young women. It has been reported that women with one or more deliveries or vaginal and/or multiple PFM lacerations are more likely to develop dysfunctions in this muscle group ${ }^{6,7)}$. Kim et al. ${ }^{8)}$ observed lower PFM pressure in young women who had normal deliveries when compared with their nulliparous counterparts, but there was no difference in PFM function between women with a history of normal deliveries and those who underwent cesareans. A study conducted with 27,900 women showed that the correlation between parity and PFM function is strong in women of reproductive age; however, there are uncertainties regarding repercussions in other periods of the female cycle ${ }^{6,9,10)}$.

Another factor that seems to be associated with PFM dysfunctions is engaging in physical activity. Reflex pelvic floor muscle contraction occurs simultaneous to the increase in abdominal pressure resulting from physical exercise, which may promote better functioning in individuals engaging in physical activity ${ }^{11}$. However, the effects of physical activity on the PFM of postmenopausal women remain controversial due to uncertainties about the repercussion of exercises at different intensities in different modalities ${ }^{12}{ }^{13}$. In reproductive-age women or during specific phases of the reproductive cycle, the literature shows that variables such as parity and vaginal delivery seem to have a negative influence on PFM function ${ }^{6,7,9,10)}$. Furthermore, a number of studies demonstrate that both high-impact exercise and sedentary behavior have harmful effects on the function of these muscles ${ }^{12,13)}$. However, in postmenopausal women doubts remain concerning the effect on this muscle group.

It is known that postmenopausal women undergo hormonal changes caused by hypoestrogenism and that these changes may provoke a decrease in PFM activity as well as the emergence of pelvic dysfunctions that compromise quality of life. However, uncertainties remain regarding the influence of factors before menopause on PFM function. Thus, the aim of this study was to investigate whether parity, type of delivery, and physical activity level influence PFM function in postmenopausal women, as well as to compare PFM function in accordance with menopausal status.

\section{SUBJECTS AND METHODS}

This was an observational, analytical study with a cross-sectional design. The sample was composed of 100 women aged between 45 and 65 years being treated at the Januário Cicco Maternity School in northeastern Brazil and was divided into three groups according to the type and time of menopause ${ }^{3)}$. The hysterectomized group $\left(\mathrm{G}_{\mathrm{HT}}\right)$ was comprised of hysterectomized women, the early postmenopausal group $\left(\mathrm{G}_{(<6)}\right)$ was comprised of women in the early postmenopausal phase, defined as a maximum time of 6 years, and the late postmenopausal group $\left(\mathrm{G}_{(>6)}\right)$ was comprised of women in the late stage of postmenopause, which was considered to be more than 6 years after the onset of menopause ${ }^{3}$.

The inclusion criteria were as follows: being in postmenopause ${ }^{3)}$, not undergoing hormone replacement therapy, no previous physical therapy for pelvic dysfunction, and not engaging in specific exercises for pelvic floor muscles. The exclusion criteria were as follows: not submitting to physical examination, having an infection, exhibiting a stage III or IV prolapse, or complaining of unbearable pain during a muscle strength test or perineometry. The sample number was previously determined for a power of $82 \%$.

Data collection occurred in three stages: (1) In the first satge, an assessment chart was used to collect information on sociodemographic data, pre-existing diseases, and urological, gynecological, and obstetric history. (2) In the second stage, a physical examination was performed to assess anthropometric measures, pelvic floor muscle function using a muscle strength test (MST), and perineometry. (3)In the third satge, the International Physical Activity Questionnaire (IPAQ) was applied to assess physical activity level. The IPAQ classifies individuals as very active, active, irregularly active, and sedentary ${ }^{14)}$. Those that complied with the following recommendations were classified as very active: a) vigorous activity: $\geq 5$ days/week and $\geq 30$ minutes per session or b) vigorous activity: $\geq 3$ days/week and $\geq 20$ minutes per session + moderate or walking $\geq 5$ days/week and $\geq 30$ minutes per session. Those that complied with the following recommendations were classified as active: a) vigorous activity: $\geq 3$ days/week and $\geq 20$ minutes per session, moderate activity or walking $\geq 5$ days/week and $\geq 30$ minutes per session, or c) any added activity $\geq 5$ days/week and $\geq 150$ hours/week (walking + moderate + vigorous). Those who engaged in physical activity but insufficiently to be classified as active were classified as irregularly active, since they did not comply with recommendations regarding frequency or duration. The frequency and duration of different activities (walking + moderate + vigorous) were totaled to determine whether subjects should be classified as irregular active. Those who did not engage in any physical activity for at least 10 continuous minutes per week were classified as sedentary ${ }^{14)}$.

For functional assessment of the pelvic floor, participants remained in the lithotomy position (dorsal decubitus with the hips and knees flexed, thighs apart, and feet in stirrups). First, the subject was instructed to contract their PFM as if they were "holding in their urine." At this time, the examiner looked for objective contraction, use of accessory muscles, execution of the Valsalva maneuver, or hip retroversion and if necessary, corrected the movement ${ }^{15)}$. Next, bidigital vaginal palpation was performed, asking subjects once again to contract their PFM, and strength was measured using the modified Oxford scale ${ }^{16)}$. This scale classifies strength from 0 to 5 , where 0 is the "absence of muscle response", 1 is "unsustained flicker", 2 is "weak contraction", 3 is "moderate contraction", 4 is "satisfactory contraction" and 5 is "strong contraction."

Perineometry was applied to assess pressure, using a Peritron ${ }^{\mathrm{TM}}$ 9300AV perineometer. The probe, lubricated with preservative and gel, was introduced into the vagina. Subjects were asked to perform three maximum voluntary contractions 30 seconds apart ${ }^{17}$ ). During the examination, values were disregarded if the patient did not properly execute the contraction. The 
arithmetic mean of the values from three maximum voluntary contractions was used as the pressure value ${ }^{18)}$.

Questionnaire application and physical assessment were conducted by two physiotherapist examiners specialized and experienced in urogynecological physiotherapy, who alternated according to the days of the week. All assessments took place between 07:00 and 09:00 hours.

The IBM SPSS 20.0 software (IBM Corp, Armonk, NY, USA) was used for statistical analysis, with the significance level set at 5\% in all statistical procedures. The Kolmogorov-Smirnov test was applied to analyze data normality, ANOVA was used to compare intergroup means, and the Kruskal-Wallis test to compare strength medians. Multiple regression was used to determine the influence of delivery type, parity, and physical activity on the pelvic floor. The intraclass correlation coefficient (ICC) was also applied to assess interexaminer reliability of perineometry. The study was approved by the Research Ethics Committee of the Federal University of Rio Grande do Norte (protocol no. 1.042.362). All the participants gave informed consent before the evaluations began.

\section{RESULTS}

A total of 100 women were initially assessed. Of them, 2 were excluded because they did not undergo the physical examination. Of the remaining 98 women, $13.3 \%(n=13)$ were unable to successfully undergo perineometry, with $61.5 \%$ of them $(n=8)$ unable because of a lack of coordinated PFM contraction and $38.5 \%(n=5)$ unable because ir was impossible to introduce the probe due to complaints of pain during the procedure. The final sample consisted of 85 women.

The three groups were homogeneous in terms of sociodemographic characteristics, except for age, the mean of which in $\mathrm{G}_{(>6)}$ was significantly higher than that in $\mathrm{G}_{(<6)}(\mathrm{p}=0.000)$. Anthropometric measures, such as body mass index and waist circumference, showed no intergroup difference $(\mathrm{p}=0.34$ and $\mathrm{p}=0.33$, respectively). Analysis of obstetric history revealed homogeneity between the three groups in relation to pregnancies and number and type of deliveries. With respect to age at menopause, the hysterectomized patients $\left(\mathrm{G}_{\mathrm{HT}}\right)$ entered menopause at an earlier age than those who experienced natural menopause $\left(\mathrm{G}_{(<6)}\right.$ and $\left.\mathrm{G}_{(>6)}\right)(\mathrm{p}=0.000)$ (Table 1$)$.

In relation to assessment of PFM function, there was no difference between the muscle strength test (MST) values and those of perineometry in postmenopausal women. The mean value obtained in perineometry was $35.9 \pm 23.6 \mathrm{cmH}_{2} \mathrm{O}$, and the mean value in the MST was 3 (Q25 2 - Q75 4) (Table 2).

Multivariate regression analysis showed that type of delivery, parity, and physical activity level exhibited no linear relation with PFM pressure in the postmenopausal women ( $\mathrm{p}=0.794)$.

The ICC for perineometry obtained a Cronbach's alpha value of $0.98(\mathrm{p}=0.000)$. This result demonstrates the strong correlation and high reliability between the two examiners.

\section{DISCUSSION}

The present study assessed the influence of parity, type of delivery, and physical activity level in postmenopausal women, obtaining important data regarding lifelong care in relation to factors that can influence PFM function. Unlike other investigations, this study evaluated PFM function directly using an MST and perineometry, making the results more reliable in terms of muscle function. Furthermore, the present study analyzed the different natural postmenopausal phases and surgical menopause, enabling a more precise assessment of the influence of menopausal status on the decline of PFM function in postmenopausal women.

Assessment of PFM pressure revealed a mean value of $35.9 \pm 23.6 \mathrm{cmH}_{2} \mathrm{O}$. This value is in line with that observed in women from this age group with good PFM function, which varied in other studies between 28.00 and $48.00 \mathrm{cmH}_{2} \mathrm{O}^{19-21)}$.

In the present study, strength and PFM pressure in early and late postmenopause showed no difference $(\mathrm{p}=0.95)$. This is the first study to evaluate PFM function in accordance with time of menopause, and it demonstrated that menopausal status seems not to be related to the decline in PFM function. Previous studies carried out with postmenopausal women did not assess PFM function with respect to the phase of postmenopause ${ }^{19-21)}$

Physical activity level showed no relation with PFM function. A number of authors have demonstrated the negative influence of high-impact physical exercise on the PFM in women and athletes ${ }^{18,22,23)}$. The intense activities engaged in adolescence may have a negative effect on urinary loss symptoms exhibited by women over the age of 50 years ${ }^{24)}$. Studies conducted by Virtuoso et al. ${ }^{25)}$ and Vinsnes et al. ${ }^{26)}$ in women with mean ages of 60 and 65 years, respectively, found that individuals with higher levels of physical activity showed higher PFM pressures when compared with those who had lower levels of activity. The former also exhibited a decline in urinary loss ${ }^{27)}$. Even though previously published data shows that physical activity level in this phase could have a positive influence on pelvic floor muscles, the studies did not take into account the previous life of the participants, nor did they categorize their samples in relation to type and intensity of physical activity, which may have interfered on their results.

Parity and type of delivery had no influence on PFM function in the postmenopausal women. We hypothesized that the presence of aging factors in this population is the primary reason for the decline in this muscle group. Our results corroborate those reported in recent articles ${ }^{27}, 28$. A prospective analysis of young women revealed that damage to the PFM is caused by their first delivery and that from their second delivery onward, there are no major changes in the biomechanics or integrity $f$ 
Table 1. The sample's sociodemographic, anthropometric, gynecologic, and obstetric characteristics

\begin{tabular}{|c|c|c|c|}
\hline & $\mathrm{G}_{\mathrm{HT}}$ & $G_{(<6)}$ & $\mathrm{G}_{(>6)}$ \\
\hline & $(n=26)$ & $(n=33)$ & $(n=26)$ \\
\hline Age (years)* & $56.12 \pm 4.13$ & $53.21 \pm 3.88^{\mathrm{a}}$ & $58.95 \pm 3.96^{\mathrm{a}}$ \\
\hline \multicolumn{4}{|l|}{ Marital status (\%) } \\
\hline Single & $7.7(n=02)$ & $12.1(\mathrm{n}=04)$ & $7.7(n=02)$ \\
\hline Single with stable union & $11.5(n=03)$ & $12.1(n=04)$ & $11.5(n=03)$ \\
\hline Married & $38.5(n=10)$ & $51.5(\mathrm{n}=17)$ & $65.4(n=17)$ \\
\hline Widow & $7.7(n=02)$ & $12.1(n=04)$ & $7.7(n=02)$ \\
\hline Divorced & $30.8(n=08)$ & $9.1(n=03)$ & $7.7(n=02)$ \\
\hline \multicolumn{4}{|l|}{ Religion (\%) } \\
\hline Catholic & $53.8(\mathrm{n}=14)$ & $51.5(\mathrm{n}=17)$ & $76.9(n=20)$ \\
\hline Evangelical & $23.1(\mathrm{n}=06)$ & $36.4(n=12)$ & $11.5(n=03)$ \\
\hline Spiritism & $3.8(\mathrm{n}=01)$ & $6.1(n=02)$ & $0(\mathrm{n}=00)$ \\
\hline Without religion & $0(\mathrm{n}=00)$ & $3.0(n=01)$ & $3.8(\mathrm{n}=01)$ \\
\hline Unknown & $19.2(\mathrm{n}=05)$ & $3.0(n=01)$ & $7.7(n=02)$ \\
\hline Family income (R\$) & $2,811.92 \pm 3,433.17$ & $2,183.54 \pm 1,660.61$ & $3,042.10 \pm 2,589.48$ \\
\hline Income per capita $(\mathrm{R} \$)$ & $1,271.83 \pm 1,748.97$ & $585.47 \pm 466.67$ & $1,120.03 \pm 952.58$ \\
\hline Weight (kg) & $67.8 \pm 10.9$ & $69.2 \pm 11.6$ & $72.5 \pm 17.2$ \\
\hline Height (m) & $1.54 \pm 0.05$ & $1.55 \pm 0.05$ & $1.54 \pm 0.06$ \\
\hline $\operatorname{BMI}\left(\mathrm{kg} / \mathrm{m}^{2}\right)$ & $28.41 \pm 4.04$ & $28.50 \pm 4.46$ & $30.27 \pm 6.53$ \\
\hline \multicolumn{4}{|l|}{ BMI (\%) } \\
\hline Normal & $26.9(\mathrm{n}=07)$ & $15.6(\mathrm{n}=05)$ & $26.9(\mathrm{n}=07)$ \\
\hline Overweight & $50.0(\mathrm{n}=13)$ & $53.1(\mathrm{n}=17)$ & $26.9(n=07)$ \\
\hline Obese & $23.1(\mathrm{n}=06)$ & $31.3(\mathrm{n}=10)$ & $46.2(n=12)$ \\
\hline Waist circumference $(\mathrm{cm})$ & $89.5 \pm 11.3$ & $92.8 \pm 10.7$ & $95.2 \pm 12.8$ \\
\hline Pregnancies & $2.92 \pm 1.49$ & $3.03 \pm 1.70$ & $2.92 \pm 2.07$ \\
\hline \multicolumn{4}{|l|}{ Mode of delivery (\%) } \\
\hline Vaginal delivery & $30.8(\mathrm{n}=08)$ & $43.8(n=14)$ & $38.5(\mathrm{n}=10)$ \\
\hline Cesareansection & $38.5(n=10)$ & $25(n=08)$ & $26.9(\mathrm{n}=07)$ \\
\hline Vaginal delivery + cesareansection & $15.3(n=04)$ & $21.9(\mathrm{n}=07)$ & $15.4(\mathrm{n}=04)$ \\
\hline Forceps & $11.5(\mathrm{n}=03)$ & $9.4(n=03)$ & $3.8(n=03)$ \\
\hline Nulliparous & $3.8(\mathrm{n}=01)$ & $0(\mathrm{n}=04)$ & $15.4(\mathrm{n}=03)$ \\
\hline \multicolumn{4}{|l|}{ Number of deliveries } \\
\hline Vaginal delivery & $1.46 \pm 1.47$ & $1.88 \pm 1.83$ & $1.85 \pm 2.24$ \\
\hline Cesareansection & $0.96 \pm 0.99$ & $0.67 \pm 0.89$ & $0.64 \pm 0.91$ \\
\hline Age at menopause (years)* & $41.48 \pm 6.9^{a . b}$ & $49.92 \pm 3.79^{\mathrm{a}}$ & $47.38 \pm 4.62^{b}$ \\
\hline Time of menopause (years)* & $14.63 \pm 8.17^{\mathrm{c}}$ & $3.28 \pm 1.58^{\mathrm{c.d}}$ & $11.57 \pm 4.62^{\mathrm{d}}$ \\
\hline
\end{tabular}

$* \mathrm{p}<0.05$ in ANOVA; averages with the same letters are statistically different

Table 2. Measures of strength and pressure of the PFM

\begin{tabular}{lcccc}
\hline & $\begin{array}{c}\text { Total } \\
(\mathrm{n}=85)\end{array}$ & $\begin{array}{c}\mathrm{G}_{\mathrm{HT}} \\
(\mathrm{n}=26)\end{array}$ & $\begin{array}{c}\mathrm{G}_{(<6)} \\
(\mathrm{n}=33)\end{array}$ & $\begin{array}{c}\mathrm{G}_{(>6)} \\
(\mathrm{n}=26)\end{array}$ \\
\hline Pressure $\left(\mathrm{cmH}_{2} \mathrm{O}\right)$ & $35.9 \pm 23.6$ & $35.7 \pm 26.5$ & $35.2 \pm 22.5$ & $37.1 \pm 22.9$ \\
Strength (modified Oxford) & $3(2-4)$ & $3(1.75-4)$ & $3(2-4)$ & $3(2-4)$ \\
\hline
\end{tabular}

Comparative analysis of $\mathrm{G}_{\mathrm{HT}}, \mathrm{G}_{(<6)}$ and $\mathrm{G}_{(>6)}$

the levator ani and, therefore, in vesical support ${ }^{27)}$. This same author reported that there is no difference in bladder neck mobility or levator hiatus size in women with normal or cesarean deliveries. Likewise, a retrospective study with women aged between 45 and 85 years found that the number of deliveries had no direct influence on PFM strength. That study suggests that the functional decline in PFM in the present study could be associated with the aging process ${ }^{28)}$. In contrast to these data, 
Özdemır et al. ${ }^{29)}$ observed that women who had 1-3 deliveries displayed better PFM pressure than those with 4-6 deliveries. However, the authors did not consider menopausal status and age. Moreover, women with 1-3 deliveries were significantly younger, and the percentage of participants in postmenopause was lower when compared with the other groups. The present study also showed no difference between women with 4-6 vaginal deliveries and those with more than 6 vaginal deliveries. The results could have been different if the sample had been assessed for age and menopausal status.

Yang et al. ${ }^{30)}$ demonstrated an association between a decline in PFM function and age, parity, and postmenopausal status, with age being the primary impact factor. Corroborating this hypothesis, Eogan et al. ${ }^{31)}$ concluded, based on analysis of the influence of type of delivery and age on PFM function in climacteric women, that age also seems to exert greater influence over these muscles, regardless of the type of delivery. Histological analysis of cadavers showed that pelvic floor tissue of the elderly was more rigid and less elastic, irrespective of previous trauma suffered ${ }^{32)}$.

As observed in the present study, parity, type of delivery, and physical activity level do not seem to have an effect on pelvic floor muscles in postmenopausal women. It is believed that the functional decline in this population is due to hormonal changes and the natural female aging process. The muscle mass loss process starts around the age of 40 years and is accompanied by reduction in the cross-sectional area, diminished strength, and changes in muscle composition caused by fat deposition, resulting in diminished functionality known as sarcopenia. In women, this occurs simultaneous to changes in menopausal status, making it more difficult to differentiate between the purely hormonal influence and the influence of the aging process ${ }^{33}$,34). Moreover, changes in estrogen levels and a decline in physical activity have been strongly associated with the physiopathology of sarcopenia. It is known that there is a positive correlation between the systemic levels of estrogen and indicators of muscle quality and strength ${ }^{34)}$. This was also observed by Micussi et al. ${ }^{35}$ ) in a study of young women with regular menstrual cycles. Electromyography showed a strong positive correlation between tonus and maximum voluntary contraction in the PFM and an increase in estradiol level.

Histological analysis revealed that during the sarcopenia process there is preferential loss of type II muscle fibers and conversion of type II fibers into type I, causing a negative impact on muscle strength and power ${ }^{33)}$. These muscle changes would therefore be responsible for the decline in PFM function in postmenopausal women, as opposed to previous obstetric factors such as parity and type of delivery.

The present study had a number of limitations, including the absence of an investigation regarding physical exercise during adolescence and early adulthood. Furthermore, physical activity level was measured with the IPAQ, which does not categorize subjects according to the type of activity performed. We also experienced difficulty with respect to the current literature, which makes no distinction between physical activity and physical exercise. The type and intensity of exercise may have a different effect on the PFM when compared with physical activity level. We therefore suggest that longitudinal studies should be performed to assess physical activity level, the type and intensity of exercise engaged in from adolescence to postmenopause, and the number and types of deliveries in order to obtain more reliable data about the influence of these variables on the PFM of postmenopausal women.

It was concluded that parity, type of delivery, and physical activity level seem to have no influence on pelvic floor muscle function in postmenopausal women. It was also observed that in terms of type and time of menopause, there was no difference between women who had artificial or natural menopause or between those in early and late postmenopause. There are strong indications that advancing age is associated with a decline in PFM function and that this is common to all women, regardless of previous obstetric conditions.

By confirming the hypothesis that the number of deliveries, vaginal delivery, and a sedentary lifestyle have no negative influence on pelvic floor muscle function in postmenopausal women, this study shows that the aging process seems to be the primary factor for the emergence of changes in PFM function, underscoring the importance of physical exercises as a means of preventing pelvic floor disorders. It is important to consider that the population is aging and the most women will experience the consequences of hormonal decline and muscle aging, irrespective of their personal history.

\section{REFERENCES}

1) Gold EB: The timing of the age at which natural menopause occurs. Obstet Gynecol Clin North Am, 2011, 38: 425-440. [Medline] [CrossRef]

2) Whitham HK, Maclehose RF, Harlow BL, et al.: Assessing the utility of methods for menopausal transition classification in a population-based cohort: the CARDIA Study. Maturitas, 2013, 75: 289-293. [Medline] [CrossRef]

3) Harlow SD, Gass M, Hall JE, et al. STRAW 10 Collaborative Group: Executive summary of the stages of reproductive aging workshop + 10: addressing the unfinished agenda of staging reproductive aging. Menopause, 2012, 19: 387-395. [Medline] [CrossRef]

4) Mishra GD, Cardozo L, Kuh D: Menopausal transition and the risk of urinary incontinence: results from a British prospective cohort. BJU Int, 2010, 106: 1170-1175. [Medline] [CrossRef]

5) Higal R, Lopes MH, Reis MJ: Fatores de risco para incontinência urinária na mulher. Rev Esc Enferm USP, 2006, 42: 
187-192. [CrossRef]

6) Hansen BB, Svare J, Viktrup L, et al.: Urinary incontinence during pregnancy and 1 year after delivery in primiparous women compared with a control group of nulliparous women. Neurourol Urodyn, 2012, 31: 475-480. [Medline] [CrossRef]

7) Memon H, Handa VL: Pelvic floor disorders following vaginal or cesarean delivery. Curr Opin Obstet Gynecol, 2012, 24: 349-354. [Medline] [CrossRef]

8) Kim H, Shim J, Kim B: Analysis of vaginal pressure and abdominal EMG according to delivery method during pelvic floor. J Phys Ther Sci, 2012, 24: 119-121. [CrossRef]

9) MacLennan AH, Taylor AW, Wilson DH, et al.: The prevalence of pelvic floor disorders and their relationship to gender, age, parity and mode of delivery. BJOG, 2000, 107: 1460-1470. [Medline] [CrossRef]

10) Rortveit G, Hannestad YS, Daltveit AK, et al.: Age- and type-dependent effects of parity on urinary incontinence: the Norwegian EPINCONT study. Obstet Gynecol, 2001, 98: 1004-1010. [Medline] [CrossRef]

11) Bø K: Urinary incontinence, pelvic floor dysfunction, exercise and sport. Sports Med, 2004, 34: 451-464. [Medline] [CrossRef]

12) Danforth KN, Shah AD, Townsend MK, et al.: Physical activity and urinary incontinence among healthy, older women. Obstet Gynecol, 2007, 109: 721-727. [Medline] [CrossRef]

13) Thyssen HH, Clevin L, Olesen S, et al.: Urinary incontinence in elite female athletes and dancers. Int Urogynecol J Pelvic Floor Dysfunct, 2002, 13: 15-17. [Medline] [CrossRef]

14) Matsudo S, Araujo T, Matsudo V, et al.: Questionário internacional de atividade física (IPAQ): estudo de validade e reprodutibilidade no Brasil. Rev Bras Ativ Fis Saude, 2001, 6: 5-18.

15) Barbosa PB, Franco MM, Souza FO, et al.: Comparison between measurements obtained with three different perineometers. Clinics (Sao Paulo), 2009, 64: 527-533. [Medline] [CrossRef]

16) Laycock J: Clinical guidelines for the physiotherapy management of females aged 16-65 years with stress urinary incontinence. London: Chartered Society of Physiotherapy, 2001.

17) Ferreira CH, Barbosa PB, de Oliveira Souza F, et al.: Inter-rater reliability study of the modified Oxford Grading Scale and the Peritron manometer. Physiotherapy, 2011, 97: 132-138. [Medline] [CrossRef]

18) Da Roza T, Mascarenhas T, Araujo M, et al.: Oxford Grading Scale vs. manometer for assessment of pelvic floor strength in nulliparous sports students. Physiotherapy, 2013, 99: 207-211. [Medline] [CrossRef]

19) Moreira EC, Arruda PB: Força muscular do assoalho pélvico entre mulheres continentes jovens e climatéricas. Semina Cienc Biol Saude, 2010, 31: 53-61. [CrossRef]

20) Pereira VS, Correia GN, Driusso P: Individual and group pelvic floor muscle training versus no treatment in female stress urinary incontinence: a randomized controlled pilot study. Eur J Obstet Gynecol Reprod Biol, 2011, 159: 465471. [Medline] [CrossRef]

21) Pereira VS, de Melo MV, Correia GN, et al.: Long-term effects of pelvic floor muscle training with vaginal cone in post-menopausal women with urinary incontinence: a randomized controlled trial. Neurourol Urodyn, 2013, 32: 48-52. [Medline] [CrossRef]

22) Schettino MT, Mainini G, Ercolano S, et al.: Risk of pelvic floor dysfunctions in young athletes. Clin Exp Obstet Gynecol, 2014, 41: 671-676. [Medline]

23) Borin LC, Nunes FR, Guirro EC: Assessment of pelvic floor muscle pressure in female athletes. PM R, 2013, 5: 189193. [Medline] [CrossRef]

24) Nygaard IE, Shaw JM, Bardsley T, et al.: Lifetime physical activity and female stress urinary incontinence. Am J Obstet Gynecol, 2015, 213: 40.e1-40.e10. [Medline] [CrossRef]

25) Virtuoso JF, Mazo GZ, Menezes EC: Urinary incontinence and perineal muscle function in physically active and sedentary elderly women. Rev Bras Fisioter, 2011, 15: 310-317. [Medline] [CrossRef]

26) Vinsnes AG, Helbostad JL, Nyrønning S, et al.: Effect of physical training on urinary incontinence: a randomized parallel group trial in nursing homes. Clin Interv Aging, 2012, 7: 45-50. [Medline] [CrossRef]

27) Horak TA, Guzman-Rojas RA, Shek KL, et al.: Pelvic floor trauma: does the second baby matter? Ultrasound Obstet Gynecol, 2014, 44: 90-94. [Medline] [CrossRef]

28) Slieker-ten Hove MC, Pool-Goudzwaard AL, Eijkemans MJ, et al.: Pelvic floor muscle function in a general female population in relation with age and parity and the relation between voluntary and involuntary contractions of the pelvic 
floor musculature. Int Urogynecol J Pelvic Floor Dysfunct, 2009, 20: 1497-1504. [Medline] [CrossRef]

29) Özdemır ÖC, Bakar Y, Özengın N, et al.: The effect of parity on pelvic floor muscle strength and quality of life in women with urinary incontinence: a cross sectional study. J Phys Ther Sci, 2015, 27: 2133-2137. [Medline] [CrossRef]

30) Yang JM, Yang SH, Huang WC, et al.: Factors affecting reflex pelvic floor muscle contraction patterns in women with pelvic floor disorders. Ultrasound Obstet Gynecol, 2013, 42: 224-229. [Medline] [CrossRef]

31) Eogan M, O'Brien C, Daly L, et al.: The dual influences of age and obstetric history on fecal continence in parous women. Int J Gynaecol Obstet, 2011, 112: 93-97. [Medline] [CrossRef]

32) Chantereau P, Brieu M, Kammal M, et al.: Mechanical properties of pelvic soft tissue of young women and impact of aging. Int Urogynecol J Pelvic Floor Dysfunct, 2014, 25: 1547-1553. [Medline] [CrossRef]

33) Basualto-Alarcón C, Varela D, Duran J, et al.: Sarcopenia and androgens: a link between pathology and treatment. Front Endocrinol (Lausanne), 2014, 5: 217. [Medline]

34) Pöllänen E, Sipilä $S$, Alen M, et al.: Differential influence of peripheral and systemic sex steroids on skeletal muscle quality in pre- and postmenopausal women. Aging Cell, 2011, 10: 650-660. [Medline] [CrossRef]

35) Micussi MT, Freitas RP, Angelo PH, et al.: Is there a difference in the electromyographic activity of the pelvic floor muscles across the phases of the menstrual cycle? J Phys Ther Sci, 2015, 27: 2233-2237. [Medline] [CrossRef] 